\title{
Laryngeal mask versus endotracheal intubation for pre-hospital emergency airway management: a meta-analysis of randomized control studies
}

Hao Li

Chinese PLA General Hospital

Ming-da Duan

Chinese PLA General Hospital

Yun-liang Zhang

Chinese PLA General Hospital

Shao-hua You

Chinese PLA General Hospital

Yu-xiang Song

Chinese PLA General Hospital

Xuan Zhang

Chinese PLA General Hospital

Min Liu

Chinese PLA General Hospital

Wen-gang Liu

Chinese PLA General Hospital

Ai-sheng Hou

Chinese PLA General Hospital

jiangbei cao ( $\sim$ cjb2000@sina.com )

Chinese PLA General Hospital

Research article

Keywords: laryngeal mask; endotracheal intubation; pre-hospital emergency; meta-analysis

Posted Date: December 30th, 2019

DOI: https://doi.org/10.21203/rs.2.15885/v3

License: (1) (1) This work is licensed under a Creative Commons Attribution 4.0 International License.

Read Full License 


\section{Abstract}

Background : Pre-hospital emergency airway management plays an important role in pre-hospital care. Laryngeal masks are increasingly employed for the airway management of pre-hospital critical patients and have achieved promising results. Although several randomized controlled trials have reported benefits, the efficacy of laryngeal masks in pre-hospital emergency airway management compared to endotracheal intubation have not been systematically reviewed. Methods: Electronic databases (PubMed, Cochrane Library, Embase, Scopus and CNKI) were searched up to April 2019 for related randomized studies. Outcome indicators included overall intubation success rates, the success rates of the first intubation, insertion time, resuscitation efficiency rates, SpO2 rise time, the blood gas index and adverse events. Two investigators selected the trials, extracted the data according to inclusion and exclusion criteria, and assessed the quality of the literature according to the Jada score. The metaanalysis was performed using stata 14.0 software. Results: We included 31 human studies. Compared to endotracheal intubation, the application of laryngeal mask for pre-hospital emergencies enhanced the resuscitation efficiency rates $[R R=1.20,95 \% \mathrm{Cl}(1.06,1.35), P<0.001]$, improved the success of first intubation $[R R=1.29,95 \% \mathrm{Cl}(1.18,1.40), \mathrm{P}<0.001]$ and the patients' blood gas index, shortened the insertion and SpO2 rise times [SMD $=-3.48,95 \% \mathrm{Cl}(-4.17,-2.80), \mathrm{P}<0.001 ;-2.19,95 \% \mathrm{Cl}(-3.06,-1.32), \mathrm{P}<$ $0.001]$ and reduced the incidence of adverse events [RR $=0.41,95 \% \mathrm{Cl}(0.30,0.57, \mathrm{P}<0.001]$. All results were stable and statistically significant. Conclusions: Laryngeal masks could quickly and effectively improve patient ventilation in pre-hospital emergencies, highlighting its utility for clinical application.

\section{Introduction}

Pre-hospital emergency airway management is crucial in pre-hospital care and is associated with the outcomes of critical patients. Effective airway management avoids systematic hypoxia and ensures organ oxygenation to reduce mortality rates and extend the time for further medical treatments of prehospital critical patients. Although tracheal intubation is regarded as an effective method to maintain pulmonary ventilation, it requires a skilled operator, precise placement and rapid responses. These factors have reduced the success rates of tracheal intubation. In particular, the success rates of tracheal intubation by non-clinical emergency personnel are generally low. In addition, tracheal intubation leads to laryngeal edema, airway injury, and other complications. Hence, some clinicians do not support tracheal intubation due to concerns over its safety and effectiveness [1].

The laryngeal mask is a novel supraglottic ventilation device that was designed based on the anatomical structure of the human pharynx, which achieves good ventilation levels without intubation. The mask can effectively reduce iatrogenic infections and pharyngeal compression injury, limiting the disruption of hemodynamics [2-3]. Recent studies reported a high efficacy of ventilation therapy when the laryngeal mask was applied to pre-hospital emergency patients. However, the majority of these studies had small sample sizes and did not adequately evaluate laryngeal mask efficacy. Hence, the effectiveness and safety of its application in pre-hospital emergency patients remains controversial [4-5]. In this study, we 
included randomized human studies to compare the ventilation effects of laryngeal masks and endotracheal intubation in pre-hospital emergencies, so as to provide reference for clinical practice.

\section{Methods}

This systematic review and meta-analysis were conducted according to the Preferred Reporting Items for Systematic Reviews and Meta-Analyses statement to report [6].

\section{Data Sources and Searches}

Electronic databases (PubMed, Cochrane Library, Embase, Scopus and CNKI) were searched up to April 2019 for related randomized studies regarding laryngeal masks versus endotracheal intubation.

References of the relevant studies were screened to incorporate studies that met the criteria. The retrieval strategy was adjusted according to different databases using the search terms: endotracheal intubation, laryngeal mask, and randomized controlled trial. The combination of mesh and free words were adopted and all retrieval strategies were determined by pre-retrieval. The search strategy of was as follows:

(Randomized) or randomized controlled study [Title/Abstract]) OR "Randomized Controlled Trial" [Publication Type])) AND (Laryngeal Mask [Title/Abstract] OR Mask, Laryngeal [Title/Abstract] OR Masks, Laryngeal [Title/Abstract] OR Laryngeal Mask [Title/Abstract] OR Airway, Laryngeal Mask [Title/Abstract] OR Airways, Laryngeal Mask [Title/Abstract] OR Laryngeal Mask [Title/Abstract]))) OR "Laryngeal Masks" [Mesh]) AND (Anesthesia, Endotracheal[Title/Abstract] OR Endotracheal Anesthesias[Title/Abstract] OR Intratracheal Anesthesia[Title/Abstract] OR Anesthesias, Intratracheal[Title/Abstract] OR Intratracheal Anesthesias[Title/Abstract] OR Anesthesia, Intratracheal[Title/Abstract] OR Endotracheal Anesthesia[Title/Abstract] OR endotracheal tube [Title/Abstract] OR tracheal tube [Title/Abstract]) OR "Anesthesia, Endotracheal"[Mesh]).

\section{Study design}

Randomization

\section{Inclusion criteria}

Pre-hospital emergency situations: the study group underwent any type of laryngeal mask management. The control group underwent endotracheal intubation.

\section{Exclusion criteria}

Non-pre-hospital emergency situations, including general anesthesia surgery, manikin studies and nonrandomization were excluded.

\section{Outcomes}

The overall intubation success rates, the success rates of first intubation, insertion times, ventilation efficiency rates, SpO2 rise times, blood gas indexes and adverse events were recorded. 


\section{Literature screening and data extraction}

Two investigators read the titles and abstracts of the retrieved studies and excluded those that failed to meet the inclusion criteria. Full texts were those that met the inclusion criteria to determine study compliance. References were cross-checked in accordance with the inclusion criteria. Disagreements were resolved through discussions. According to the pre-designed form, the research contents mainly included: (1) general information: title of the article, author's name, source of the publications and time of the publications; (2) the characteristics of the research: the research object, study baseline comparability, and interventions; (3) the observation index: overall intubation success rates, the success rate of the first intubation and insertion time.

\section{Quality assessment}

The Jada scale was used to evaluate randomized research methods, blind methods, a loss of follow-up and withdrawal. The score was 0 to $5, \leq 2$ points were classified as low-quality studies, and $\geq 3$ points were classified as high-quality studies. An independent quality assessment of the included literature was performed by two individuals and conducted and checked. Studies with inconsistent evaluations were identified through discussions and confirmed by a third reviewer.

\section{Data Analysis}

Stata 14.0 statistical software was used for meta-analysis. Continuous variables were expressed as mean standard differences ( $m \pm S D / S M D$ ) due to non-uniform units. If an article provided only the median and interquartile range (IQR), SD values were calculated according to the Cochrane manual equation: $\mathrm{SD}=\mathrm{IQR} / 1.35$ [7]. Dichotomous variables were expressed as a risk ratio (RR). The $95 \%$ feasible interval $(\mathrm{Cl})$ was calculated for both effect sizes. Heterogeneity analysis was performed using Chi-square (x2) tests. When $\mathrm{P}<0.05$ and $\mathrm{I} 2>50 \%$, heterogeneity existed between the studies. If no heterogeneity was observed, the fixed effect model was used. In other cases, the random effects model was employed. Subgroup analysis was conducted to explore the source of heterogeneity, such as environment and participant identity. Descriptive analysis was used if the sources of heterogeneity were not identified. Sensitivity analysis was performed through altering the effect model. Publication bias was assessed using funnel plots and Egger's tests to determine reliability. If bias existed, metatrim methods were performed.

\section{Results}

\section{Study characteristics and quality assessment}

According to the search strategy, a total of 996 related articles were retrieved. A total of 292 articles were excluded after duplicates were removed and 673 articles were firstly included. After reading titles, abstracts and full texts, 667 articles were excluded, of which 35 were reviews. A total of 14 reports, 532 non-pre-hospital emergency studies, 40 that did not use laryngeal masks, 36 with non-randomized data, 7 
with insufficient data and 9 randomized manikin studies were excluded. Finally, 31 randomized human studies [8-38] were included. The included studies focused on cases of cardiac arrest, respiratory failure, coma and other critical illnesses, and adverse effect mainly included laryngeal edema and mucosal hemorrhage, bucking, tooth loss and aspiration. All endotracheal intubations in the included studies were performed with direct laryngoscopes. Flow diagrams for the literature selection are shown in Figure 1. The study characteristics are shown in Table 1.

\section{Meta-Analysis of laryngeal mask vs endotracheal intubation}

\section{Ventilation efficiency rates}

Meta-analysis of 17 randomized studies [8-22, 18-20, 23 25, 27, 29-31, 33] showed that the ventilation efficiency rates of the laryngeal mask groups were higher than those of the endotracheal intubation groups $[R R=1.20,95 \% \mathrm{Cl}(1.06,1.35), P<0.001]$ without heterogeneity $\left(P=0.941, I^{2}=0 \%\right)$ (Figure 2$)$.

\section{Success rate of overall intubation s and first intubation}

A total of $19[8,11-14,16,19-20,24-28,30-33,35-36]$ and 3 randomized studies $[26,32,37]$ reported the success rates of first intubation and overall intubation success rates, respectively. The results suggested that the success rates of first intubation for the laryngeal mask were higher than those for endotracheal intubation $[R R=1.29,95 \% \mathrm{Cl}(1.18,1.40), P<0.001]$ without heterogeneity $\left(P=0.840, I^{2}=0 \%\right)$. However, no statistical differences in overall intubation success rates were observed $[R R=1.11,95 \% \mathrm{Cl}(0.88,1.39)$, $P<0.001]$ without heterogeneity $\left(P=0.979, I^{2}=0 \%\right)$ (Figure 3$)$.

Insertion time and $\mathrm{SpO}_{2}$ rise time

A total of $27[8,11-22,24-28,30-38]$ and 3 studies $[8,11,24]$ reported insertion and $\mathrm{SpO}_{2}$ rise times, respectively. The results suggested that both were shorter in the laryngeal mask groups compared to endotracheal intubation [SMD $=-3.48,95 \% \mathrm{Cl}(-4.17,-2.80), \mathrm{P}<0.001 ;-2.19,95 \% \mathrm{Cl}(-3.06,-1.32), \mathrm{P}<0.001]$ but with significant heterogeneity $\left(P=0.000, I^{2}=96.8 \% ; P=0.001, I^{2}=85.5 \%\right)$ (Figure 4$)$.

Blood gas index

Three studies $[10,23,28]$ reported $\mathrm{PaCO}_{2}, \mathrm{PaO}_{2}$ and $\mathrm{pH}$, and 8 studies $[10,14,16-17,23,28,35,38]$ reported $\mathrm{SpO}_{2}$. The pooled results showed that laryngeal mask ventilation increased $\mathrm{pH}[\mathrm{SMD}=3.74,95 \%$ $\left.\mathrm{Cl}(0.68,6.80), \mathrm{P}<0.001, \mathrm{I}^{2}=97.4 \%\right], \mathrm{PaO}_{2}\left[\mathrm{SMD}=2.9395 \% \mathrm{Cl}(1.43,4.42), \mathrm{P}<0.001, \mathrm{I}^{2}=91.4 \%\right]$ and $\mathrm{SpO}_{2}$ $\left[S M D=1.07,95 \% \mathrm{Cl}(0.11,2.04), \mathrm{P}<0.001, \mathrm{I}^{2}=95.8 \%\right]$ and lowered $\mathrm{PaCO}_{2}[\mathrm{SMD}=-4.03,95 \% \mathrm{Cl}(-5.32$, $\left.-2.73), P<0.001, I^{2}=83.1 \%\right]$ (Figure 5).

Overall adverse events and aspiration 
Thirteen $[8,11-14,19,22-25,27-29,31,34]$ and five studies $[8,11,22,28,31]$ reported the incidence rates of overall adverse events and aspiration, respectively. These suggested that laryngeal mask ventilation could reduce the occurrence of adverse events compared to endotracheal intubation $[R R=0.41,95 \% \mathrm{Cl}$ $\left(0.30,0.57, P<0.001, I^{2}=0\right]$. No differences in aspiration were observed (Figure 6).

\section{Subgroup analysis}

Due to the existence of heterogeneity, we performed subgroup analysis on the first success rates of the first insertion and insertion time. As shown in Table 2, we failed to identify any source of heterogeneity in insertion times across the included studies.

\section{Sensitivity analysis and publication bias}

The results of sensitivity analysis and publication bias are shown in Table 3. Funnel plots of included studies are shown in Figure 6. Sensitive analysis suggested that all the results were stable. Egger's tests showed the presence of publication bias in the ventilation efficiency rates and insertion times, but metatrim suggested that the bias had no influence on the final results.

\section{Discussion}

To our knowledge, this is the first systematic review and meta-analysis to compare the clinical effects of laryngeal mask placement and endotracheal intubation for pre-hospital emergencies. Our study showed that the overall effects of the laryngeal mask ventilation were superior to endotracheal intubation. Sensitivity analysis and publication bias tests also suggested that the results were stable and reliable.

The clinical application of the laryngeal mask for pre-hospital emergencies has unique advantages including its ease of use and the ability to rapidly maintain the airways. Even when the position of the laryngeal mask was not ideal, it can maintain airway patency [39]. A secondly advantage is that no laryngoscopes are needed. Compared to endotracheal intubation, it is easy for beginners to insert the laryngeal mask and the success rates are relatively high [40]. Thirdly, the laryngeal mask is used as a supraglottic ventilation device, which has the advantage of establishing the airways for autonomous ventilation and ventilation control, thus avoiding mucosal damage in the trachea. Ventilation management through endotracheal intubation is not satisfactory. Cobas et al [41] reported that the failure rates of non-anesthesiologists for endotracheal intubation can be as high as $31 \%$. Even with experienced clinicians, the misalignment rates were as high as 17.4 . \%, of which the esophageal insertion rates were $6.7 \%$ [42]. This can be fatal for comatose patients.

Our meta-analysis showed that the success rates of first intubation in the laryngeal mask group were significantly higher than the control group, and the time taken for laryngeal mask placement was significantly shorter. These results indicate that the laryngeal mask had improved success rates for first intubation. Unlike endotracheal intubation, the use of a laryngeal mask does not involve glottis exposure, is easy to operate, and easy to master. Furthermore, its shorter placement times are beneficial to the early 
recovery of the patient's ventilator function. Hypoxia in the brain tissue for more than 5 minutes can lead to irreversible brain damage; thus, establishing airway ventilation as early as possible is key to successful cardiopulmonary resuscitation. Brimacombe et al [43] reported that medical staff without experience in laryngeal mask placements were more likely to insert laryngeal masks with shorter insertion times, which was similar to our subgroup analysis. The clinical medical students of the included studies had no experience in the use of laryngeal masks, and some nurses and EMT lacked systematic training. The laryngeal mask insertion time was however shorter than that of endotracheal intubation. Subgroup analyses also suggested that paramedics, anesthesiologists, nurses, and emergency physicians have shorter insertion times for laryngeal masks in both stationary and mobile environments. The success rates of first intubation and insertion time in the laryngeal mask groups were superior to the endotracheal intubation groups, further demonstrating the advantages of the laryngeal mask. The application of the laryngeal mask in pre-hospital emergency patients benefits the early recovery of tracheal ventilation, and promotes the success of cardiopulmonary resuscitation. The drawbacks include the lack of data in the included studies.

Laryngeal mask ventilation also improved the blood gas index, leading to higher levels of $\mathrm{PaO}_{2}$ and $\mathrm{SpO}_{2}$ and shorter $\mathrm{SpO}_{2}$ rise times, which are important to ensure good patient prognosis.

The risk of bias in included studies was primarily in the blinding method, which could not be implemented. Due to the small sample size, we performed Egger's tests. The results showed that the small sample effect did not influence the final data outcomes. Moreover, specific information of the human studies was unknown due to random grouping.

The study had some limitations. First, the quality of the evidence in the included studies was weak. Secondly, the sources of heterogeneity for the comparison of first intubation success rates and insertion times were not clearly identified. Thirdly, we failed to study the different methods of laryngeal masks and endotracheal intubation. Moreover, the update of the laryngeal mask was rapid with standard types, intubable types, esophageal drainage types and no cuff types. The application of these different laryngeal masks in pre-hospital emergencies also requires further exploration. Finally, "in-the-field-time" is important for pre-hospital emergencies, but we failed to explore it due to insufficient data.

\section{Conclusions}

In summary, the application of laryngeal mask for pre-hospital emergencies could enhance the success rates of first-pass intubation, reduce the placement time and decrease the incidence of pharyngeal edema, tooth loss or injury, and other complications compared to endotracheal intubation. Laryngeal masks are therefore a more effective ventilation device and should be employed in pre-hospital emergencies. Further high-quality randomized controlled trials are now required to further demonstrate the reliability of our conclusions.

\section{Abbreviations}


Laryngeal mask, LM; Endotracheal intubation, El; Mean standard difference, SMD; Interquartile range, IQR; Standard difference, SD; Risk ratio, RR; Confidence interval, $\mathrm{Cl}$.

\section{Declarations}

\section{Ethics approval and consent to participate}

Not applicable.

\section{Consent for publication}

Not applicable.

\section{Availability of data and materials}

All data generated or analyzed during this study are included in this published article.

\section{Competing interests}

There are no competing interests for publication of this paper.

\section{Funding}

This study was supported by the 12th Five-year medical science research foundation of PLA (CWS14J068).

\section{Authors'contributions}

JB. $C$ and $H$. L had full access to all the data in the study and take responsibility for the integrity of the data and the accuracy of the data analysis. JB. C and MD. D conceived and designed the study; YX. S, X. $Z, M$. L, WG. L and AS. H led the acquisition, analysis, or interpretation of data; H. L and MD. D drafted the manuscript, YL. Z and SH. Y, checked this work again. All authors read and approved the final manuscript.

\section{Acknowledgements}

Not applicable.

\section{References}

1. Chien LC, Hsu HC, Lin $\mathrm{CH}$, et al. Use of an intubating laryngeal mask on out-of-hospital cardiac arrest patients in a developing emergency medical service system. J Formos Med Assoc. 2012;111(1):24-9.

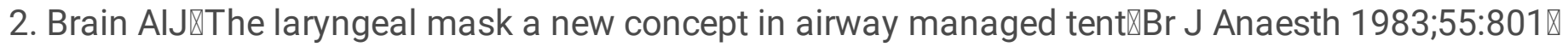

3. Tentillier E, Heydenreich C, Cros AM. Use of the intubating laryngeal mask in emergency pre-hospital difficult intubation. Resuscitation. 2008;77(1):30-4. 
4. Shahla K, Ali A, Arash H, et al. Comparing the Effectiveness of Airway Management Devices in PreHospital Emergency Care: a Randomized Clinical Trial. Pak J Med Sci, 1969;31(4).

5. Crewdson K, Rehn M, Lockey D. Airway management in pre-hospital critical care: a review of the evidence for a 'top five' research priority. Scand J Trauma Resusc Emerg Med. 2018;26:89.

6. Liberati A, Altman DG, Tetzlaff J, et al. The PRISMA statement for reporting systematic reviews and meta-analyses of studies that evaluate health care interventions: explanation and elaboration. PLoS Med. 2009;6(7):e1000100.

7. Higgins, Julian PT. Cochrane handbook for systematic reviews of interventions. Wiley-Blackwell, 2008.

8. Ding Y, Cui Y. Comparison of nursing effects between laryngeal mask and tracheal intubation in emergency department cardiopulmonary resuscitation. Xinjiang Medical Journal. 2016;46(8):10281029.

9. Gou JC, Xun CM, Xiao J, et al. Application of laryngeal mask ventilation technique in cardiopulmonary resuscitation. Chinese Journal of Disaster Medicine. 2017;(4).

10. Gao J, Wang R, Shen YL, et al. The effect of laryngeal mask on the application of pre-hospital first aid in patients with deep coma. People's Military Surgeon. 2015;(1):51-52.

11. Huang XM. Comparison of nursing effects between laryngeal mask and tracheal intubation in emergency department cardiopulmonary resuscitation. Journal of Taishan Medical College. 2016;37(2):223-225

12. Li PL, Wang AQ, Dong XX, et al. Effect of laryngeal mask-tracheal intubation on the treatment of patients with emergency cardiopulmonary resuscitation. Diabetes World. 2018;15(8):137-138.

13. Liu JS. Comparative observation on the effect of laryngeal mask and tracheal intubation in patients with cardiac arrest in pre-hospital emergency. Clinical Application Research. 2018;(12).

14. Long P, Zeng PH, Shi JX, et al. Comparison of the application of laryngeal mask and tracheal intubation in pre-hospital and emergency first aid patients with respiratory failure. Progress in Modern Biomedicine. 2018;18(24):129-132.

15. Lu JJ. Comparison of regimens for pre-hospital referral airway management in comatose patients. China Prac Med. 2012;07(3):47-48.

16. Qin G. Comparison of the effects of laryngeal mask placement and tracheal intubation on prehospital emergency treatment. Journal of Clinical Medical. 2017;(07):60+63.

17. Qiu GJ. Superiority of laryngeal mask in the pre-hospital emergency than tracheal intubation. Journal of Clinical Medical. 2018;5(87):68.

18. Shi DZ, Lin SH. Analysis of the effect of different ventilation methods on the treatment of patients with emergency cardiopulmonary resuscitation. Journal of Clinical Medical. 2018;(21).

19. Sun DJ. Clinical application of laryngeal mask and tracheal intubation in critically ill first aid. Journal of Clinical Medical. 2017;(05):49. 
20. Tang H. Application analysis of the use of laryngeal mask and tracheal intubation in emergency department cardiopulmonary resuscitation. Journal of Clinic Nursing's Practicality. 2018;3(43):124.

21. Tang XM, Du P. Comparison of sequential airway opening and tracheal intubation in prehospital coma patients. Medical Information. 2017;(7).

22. Tu XQ. Application of laryngeal mask ventilation technique in first aid cardiopulmonary resuscitation in emergency hospital. Medical Information. 2018;31(06):93-95.

23. Wang Q. Clinical effect of laryngeal mask in pre-hospital emergency treatment for patients with deep coma. Medical Information. 2017;30(6).

24. Yan H, Li B. Clinical application of SLIPA laryngeal mask in emergency treatment outside hospital. Beijing First Aid Center. 2017;(01):73-75.

25. Yuan YZ, Hao YL, Wang XS. Comparative study of laryngeal mask and tracheal intubation in prehospital emergency treatment of patients with severe craniocerebral injury and coma. Chinese Remedies \& Clinics. 2017;(2).

26. Huang X, Zhou J. Clinical study of SLIPA laryngeal mask in pre-hospital first aid rapid open airway. Journal of Gannan Medical University. 2013;(6):905-905.

27. Li H, Qi ZZ, Li XB, et al. Application of laryngeal mask and tracheal intubation in pre-hospital emergency. Sichuan Medical Journal. 2013;34(6):780-781.

28. Liang J, Gao ZF, Wang DH. Analysis of application effect of laryngeal mask on emergency difficult airway in front of hospital. Journal of Qiqihar University of Medicine. 2016;(4):443-444.

29. Liang ZM, Li H, Luo L, et al. Clinical application effect of laryngeal mask on pre-hospital emergency in patients with deep coma. Chinese and Foreign Medical Research. 2016;(2):146-147.

30. Sha JH, Zhao XW, Diao PS. The application of laryngeal mask in pre-hospital critical illness first aid. China Mecdine. 2011;06(4).

31. Wu Y, Gong XF. Application of laryngeal mask in pre-hospital emergency of critically ill patients. Journal of Clinical Medical. 2014;(5):742-742.

32. Xia FF. Feasibility of SLIPA Laryngeal Mask in Pre-hospital First Aid for Rapid Open Airway Management. Asia-Pacific Traditional Medicine. 2013;(2):85-86.

33. Yang DM, Yang XF, Wang HB, et al. Application of SLIPA laryngeal mask in pre-hospital emergency patients. Chin J Postgrad Med. 2011;34(12):43-44.

34. Yang Y, Teng T, Wang J. Analysis of application effect of intubated laryngeal mask ventilation in prehospital emergency. China J Prim Med Pharm. 2016;23(19):3026-3028.

35. Zhou L, Yang T, Li S, et al. Comparison of laryngeal mask and tracheal intubation in pre-hospital emergency ventilation. Nurs J Chin PLA. 2013;30(20):75-76.

36. Zhou XH, Cheng J, Zhang JR, et al. Clinical study of laryngeal mask in front of hospital for first aid and endangered patients. Health World. 2016;6(5):46-47.

37. Deakin CD, Peters R, Tomlinson P, et al. Securing the prehospital airway: a comparison of laryngeal mask insertion and endotracheal intubation by UK paramedics. Emerg Med J. 2005;22(1):64-67. 
38. Shahla K, Ali A, Arash H, et al. Comparing the Effectiveness of Airway Management Devices in PreHospital Emergency Care: a Randomized Clinical Trial. Pak J Med Sci. 2015;31(4).

39. Benger J, Coates D, Davies S, et al. Randomised comparison of the effectiveness of the laryngeal mask supreme, i-gel and current practice in the first airway management of out of hospital cardiac arrest: a feasibility study. Br J Anaesth. 2016;116:262-8.

40. Bosch J, de Nooij J, de Visser M, et al. Prehospital use in emergency patients of a laryngeal mask by ambulance paramedics is a safe and effective alternative for endoendotracheal intubation. Emerg Med J. 2014;31:750-753.

41. Cobas MA, de la Peña MA, Manning R, et al. Prehospital intubations and mortality: a level 1 trauma center perspective. Anesth Analg. 2009;109:489-493.

42. Timmermann A, Russo SG, Eich C, Roessler M, Braun U, Rosenblatt WH, Quintel M. The out-ofhospital esophageal and endobronchial intubations performed by emergency physicians. Anesth Analg. 2007;104:619-623.

43. Brimacombe J. The advantages of the LM over the endotracheal tube or facemask: a meta-analysis. Can J Anaesth. 1995;42:1017-1023.

\section{Tables}

Table 1. Characteristics of included studies 


\begin{tabular}{|c|c|c|c|c|c|c|}
\hline Author, year & Country & LMA(n) & ET(n) & Indication & Outcomes & Jada \\
\hline Y Ding, $2016^{8}$ & China & 40 & 40 & Cardiac arrest & $\mathrm{B}, \mathrm{C}, \mathrm{D}, \mathrm{E}$ & 4 \\
\hline JC Gou, $2017^{9}$ & China & 40 & 40 & Cardiac arrest & $\mathrm{D}$ & 4 \\
\hline J Gao, $2015^{10}$ & China & 41 & 41 & Deep coma & $\mathrm{D}, \mathrm{F}, \mathrm{G}, \mathrm{H}, \mathrm{I}$ & 4 \\
\hline XM Huang, $2016^{11}$ & China & 40 & 40 & Cardiac arrest & $B, C, D, E$ & 4 \\
\hline PL Li, $2018^{12}$ & China & 47 & 47 & Cardiac arrest & B, C, D & 4 \\
\hline JS Liu, $2017^{13}$ & China & 34 & 34 & Cardiac arrest & B, C, D & 4 \\
\hline P Long, $2018^{14}$ & China & 47 & 45 & Respiratory failure & $\mathrm{B}, \mathrm{C}, \mathrm{D}, \mathrm{I}$ & 4 \\
\hline JJ Lu, $2012^{15}$ & China & 41 & 50 & Coma & $\mathrm{C}$ & 5 \\
\hline G Qin, $2017^{16}$ & China & 27 & 27 & Critical illness & $\mathrm{B}, \mathrm{C}, \mathrm{I}$ & 5 \\
\hline GJ Qiu, $2018^{17}$ & China & 15 & 15 & Critical illness & C, I & 4 \\
\hline DZ Shi, $2018^{18}$ & China & 90 & 90 & Cardiac arrest & C, D & 5 \\
\hline DJ Sun, $2017^{19}$ & China & 30 & 30 & Critical illness & B, C, D & 4 \\
\hline H Tang, $2018^{20}$ & China & 20 & 20 & Cardiac arrest & B, C, D & 4 \\
\hline XM Tang, $2017^{21}$ & China & 82 & 100 & Coma & $\mathrm{C}$ & 4 \\
\hline XQ Tu, $2018^{22}$ & China & 45 & 45 & Cardiac arrest & $\mathrm{C}$ & 4 \\
\hline Q Wang, $2017^{23}$ & China & 20 & 20 & Deep coma & $\mathrm{D}, \mathrm{F}, \mathrm{G}, \mathrm{H}, \mathrm{I}$ & 4 \\
\hline H Yan, $2017^{24}$ & China & 35 & 35 & Respiratory failure & $\mathrm{B}, \mathrm{C}, \mathrm{E}$ & 4 \\
\hline YZ Yuan, $2017^{25}$ & China & 30 & 32 & Deep coma & B, C, D & 4 \\
\hline X Huang, $2013^{26}$ & China & 25 & 25 & Coma & $A, B, C$ & 4 \\
\hline $\mathrm{H} \mathrm{Li}, 2013^{27}$ & China & 99 & 84 & Respiratory failure & B, C, D & 5 \\
\hline J Liang, $2016^{28}$ & China & 30 & 30 & Critical illness & $B, C, F, G, H, I$ & 4 \\
\hline ZM Liang, $2016^{29}$ & China & 28 & 28 & Deep coma & $\mathrm{D}$ & 4 \\
\hline JH Sha, $2011^{30}$ & China & 35 & 30 & Critical illness & B, C, D & 4 \\
\hline $\mathrm{Y} \mathrm{Wu}, 2014^{31}$ & China & 40 & 40 & Critical illness & B, C, D & 5 \\
\hline FF Xia, $2013^{32}$ & China & 18 & 18 & Coma & $A, B, C$ & 4 \\
\hline DM Yang, $2011^{33}$ & China & 28 & 28 & Critical illness & B, C, D & 4 \\
\hline Y Yang, $2016^{34}$ & China & 30 & 30 & Respiratory failure & $\mathrm{C}$ & 4 \\
\hline L Zhou, $2013^{35}$ & China & 96 & 104 & Critical illness & $\mathrm{B}, \mathrm{C}, \mathrm{I}$ & 5 \\
\hline XH Zhou, $2016^{36}$ & China & 73 & 79 & Cardiac arrest & $\mathrm{B}, \mathrm{C}$ & 4 \\
\hline CD Deakin, $2005^{37}$ & Iran & 52 & 52 & Airway management & A, C & 5 \\
\hline S Khosravan, $2015^{38}$ & UK & 18 & 17 & Critical illness & C, I & 4 \\
\hline
\end{tabular}

A, overall intubation success rate; B, success rate of first intubation; C, insertion time; D, ventilation efficiency rate; E, SpO2 rise time; F, PaCO2; G, $\mathrm{PaO} 2 ; \mathrm{H}, \mathrm{pH} ; \mathrm{I}, \mathrm{SpO} 2$.

Critical illness: Cardiac arrest and respiratory failure 
Table 2. Results summary for subgroup analysis

\begin{tabular}{ccccc}
\hline Subgroup (effect size) & Number & Effect value & \multicolumn{2}{c}{ Heterogeneity } \\
\cline { 3 - 5 } & & & $\mathrm{I}^{2}$ & $\mathrm{P}$ \\
\hline Insertion time & & & & \\
(mean standard difference) & & & & \\
\hline $\begin{array}{c}\text { Cause } \\
\text { Cardiac arrest }\end{array}$ & 632 & $-4.01(-5.60,-2.53 \square$ & 97.2 & 0.000 \\
\hline $\begin{array}{c}\text { Respiratory failure } \\
\text { Coma }\end{array}$ & 405 & $-4.26(-5.45,-3.06)$ & 91.0 & 0.000 \\
\hline Year & 420 & $-1.96(-2.81,-1.12)$ & 91.3 & 0.000 \\
\hline$\square 50$ & 800 & $-3.11(-4.12,-2.10)$ & 95.8 & 0.000 \\
\hline$\square 50$ & 1017 & $-4.19(-5.44,-2.95)$ & 97.4 & 0.000 \\
\hline
\end{tabular}

Table 3. Results summary for sensitive analysis after changing effect model and publication bias (Egger's test)

\begin{tabular}{cccc}
\hline Sensitive analysis & Effect size & [Effect value(95\%CI), P] & Egger's test(P) \\
\hline Human studies & & & \\
\hline Ventilation efficiency rate & RR & {$[1.18(1.04,1.32), 0.007]$} & 0.001 \\
\hline $\begin{array}{c}\text { Success rate of initial intubation } \\
\text { Insertion time }\end{array}$ & RR & {$[1.27(1.16,1.38), 0.000]$} & 0.089 \\
\hline
\end{tabular}

\section{Figures}




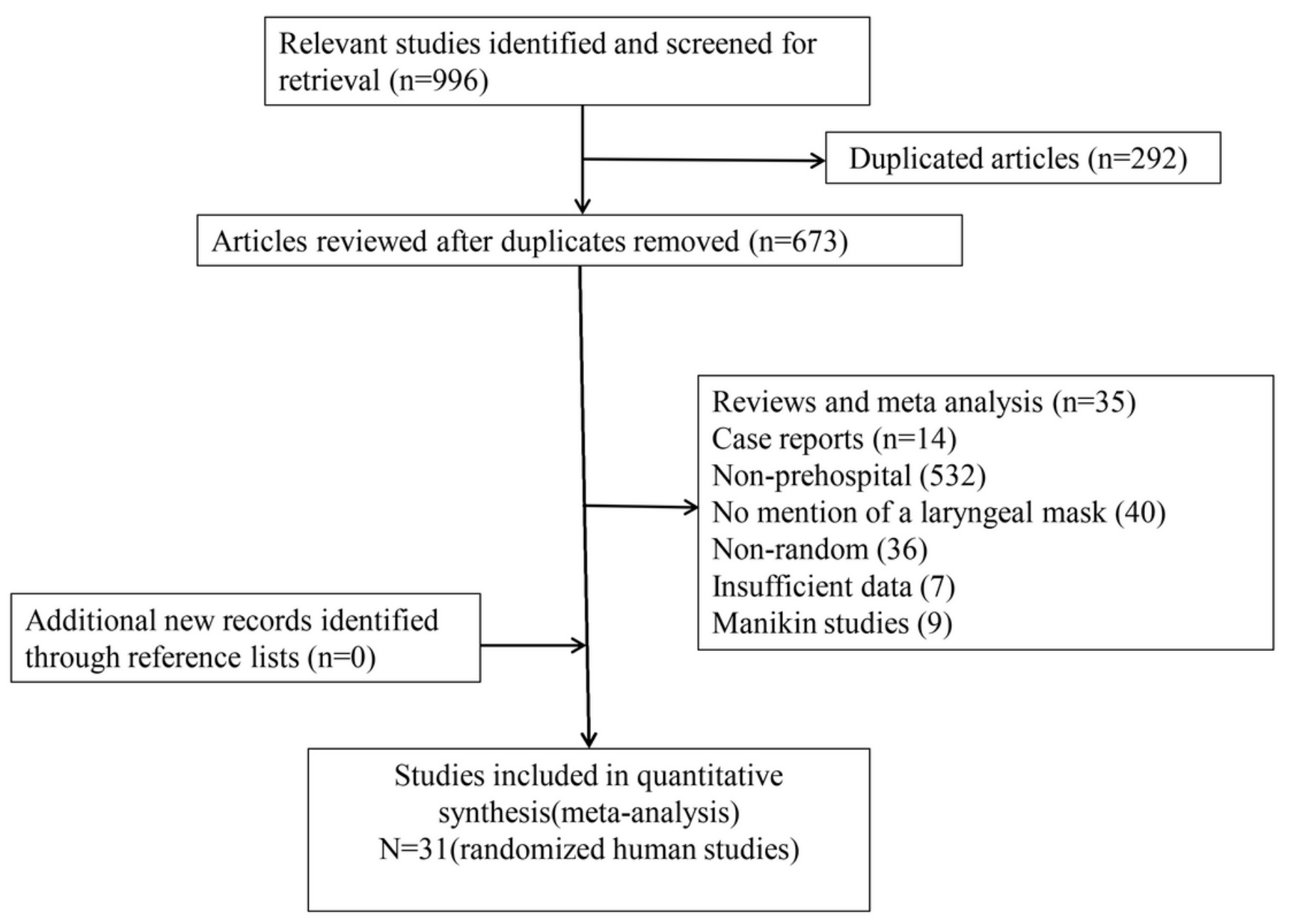

Figure 1

Flow diagram for the literature selection. 
Study

ID
JC Xun 2017

J Gao 2015

XM Huang 2016

PL Li 2018

JS Liu 2017

P Long 2018

DZ Shi 2018

H Tang 2018

Q Wang 2017

YZ Yuan 2017

H Li 2013

ZM Liang 2016

JH Sha 2011

Y Wu 2014

DM Yang 2011

DJ Sun 2017

Overall $(\mathrm{I}$-squared $=0.0 \%, p=0.941)$
$\operatorname{RR}(95 \% \mathrm{Cl})$

$\%$

Weight

$1.55(0.91,2.66) \quad 4.85$

$1.02(0.70,1.47) \quad 9.76$

$1.11(0.79,1.55) \quad 10.78$

$1.55(0.91,2.66) \quad 4.85$

$1.36(0.86,2.14) \quad 6.77$

$1.33(0.82,2.14) \quad 5.79$

$1.01(0.72,1.41) \quad 11.53$

$1.04(0.60,1.80) \quad 5.06$

$1.13(0.65,1.97) \quad 4.24$

$1.18(0.71,1.98) \quad 4.68$

$1.77(0.80,3.94) \quad 2.32$

$1.04(0.76,1.42) \quad 15.36$

$1.49(0.61,3.67) \quad 1.98$

$3.65(0.43,30.89) \quad 0.33$

$1.37(0.78,2.40) \quad 4.68$

$1.49(0.61,3.67) \quad 1.98$

$1.04(0.60,1.80) \quad 5.06$

$1.20(1.06,1.35) \quad 100.00$

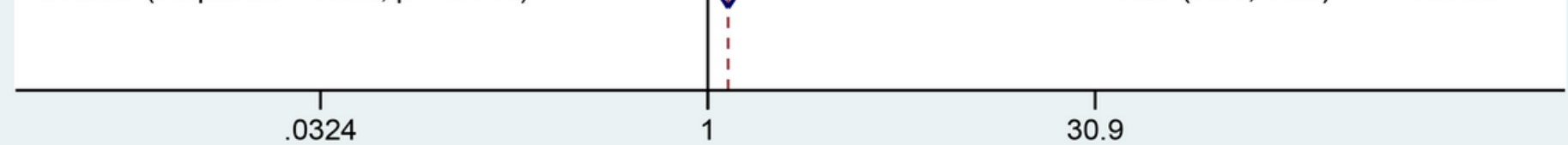

\section{Figure 2}

Forest plot of the ventilation efficiency rates. 
Study

ID

Success rate of the first intubation

Y Ding 2016

XM Huang 2016

PL Li 2018

JS Liu 2017

P Long 2018

G Qin 2017

DJ Sun 2017

H Tang 2018

H Yan 2017

YZ Yuan 2017

$X$ Huang 2013

H Li 2013

J Liang 2016

JH Sha 2011

Y Wu 2014

FF Xia 2013

L Zhou 2013

DM Yang 2011

XH Zhou 2016

Subtotal $($ I-squared $=0.0 \%, p=0.840$ )

Overall intubation success rate

CD Deakin 2005

X Huang 2013

FF Xia 2013

Subtotal $($ I-squared $=0.0 \%, p=0.979$ )

Overall (I-squared $=0.0 \%, p=0.896$ )
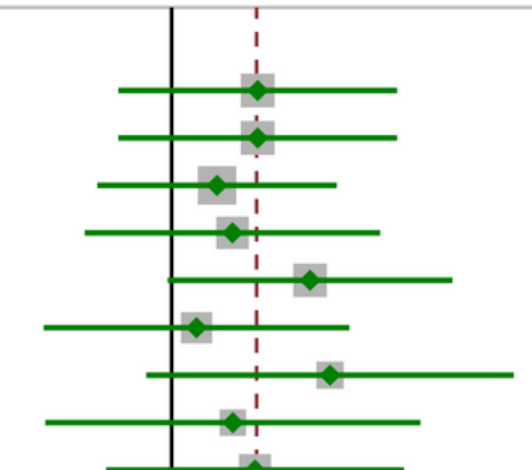

$\operatorname{RR}(95 \% \mathrm{Cl})$
$\%$

Weight
$1.27(0.86,1.86) \quad 4.50$

$1.27(0.86,1.86) \quad 4.50$

$1.13(0.82,1.57) \quad 6.08$

$1.18(0.79,1.77) \quad 4.05$

$1.46(0.99,2.16) \quad 4.39$

$1.07(0.70,1.63) \quad 3.74$

$1.54(0.93,2.56) \quad 2.65$

$1.18(0.71,1.98) \quad 2.47$

$1.26(0.84,1.89) \quad 3.95$

$1.44(0.91,2.28) \quad 3.09$

$1.48(0.85,2.56) \quad 2.24$

$1.59(1.18,2.14) \quad 7.73$

$1.23(0.80,1.88) \quad 3.57$

$1.86(1.01,3.40) \quad 1.93$

$1.14(0.80,1.62) \quad 5.22$

$1.18(0.67,2.07) \quad 2.10$

$1.05(0.86,1.29) \quad 15.28$

$1.21(0.76,1.91) \quad 3.18$

$1.56(1.14,2.13) \quad 6.79$

$1.29(1.18,1.40) \quad 87.44$

$1.13(0.82,1.56) \quad 6.40$

$1.10(0.71,1.70) \quad 3.44$

$1.06(0.66,1.72) \quad 2.72$

$1.11(0.88,1.39) \quad 12.56$

$1.26(1.16,1.37) \quad 100.00$

Figure 3

Forest plot of the overall intubation success rates and success rates of the first intubation. 


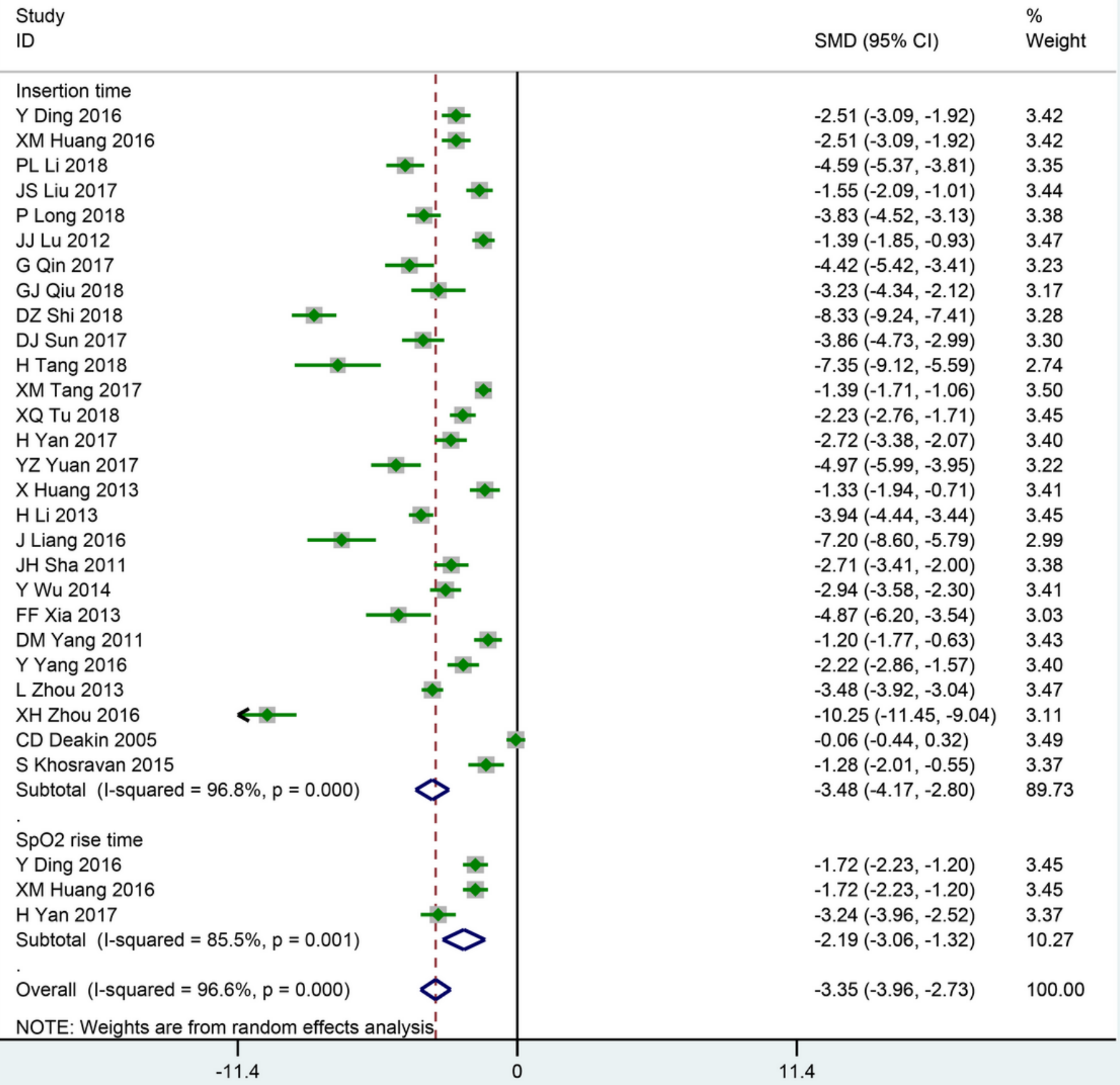

\section{Figure 4}

Forest plot of the insertion time and $\mathrm{SpO} 2$ rise time. 
Study

ID

$\mathrm{pH}$

J Gao 2015

Q Wang 2017

J Liang 2016

Subtotal $($ I-squared $=97.4 \%, p=0.000)$

$\mathrm{PaCO} 2$

J Gao 2015

Q Wang 2017

J Liang 2016

Subtotal $(\mathrm{I}$-squared $=83.1 \%, p=0.003$ )

$\mathrm{PaO} 2$

J Gao 2015

Q Wang 2017

J Liang 2016

Subtotal $(\mathrm{I}$-squared $=91.4 \%, \mathrm{p}=0.000$ )

$\mathrm{SpO} 2$

J Gao 2015

P Long 2018

G Qin 2017

GJ Qiu 2018

Q Wang 2017

J Liang 2016

L Zhou 2013

S Khosravan 2015

Subtotal $(\mathrm{I}$-squared $=95.8 \%, p=0.000$ )

Overall (I-squared $=97.8 \%, p=0.000$ )

NOTE: Weights are from random effects analysis
SMD $(95 \% \mathrm{Cl}) \quad$ Weight
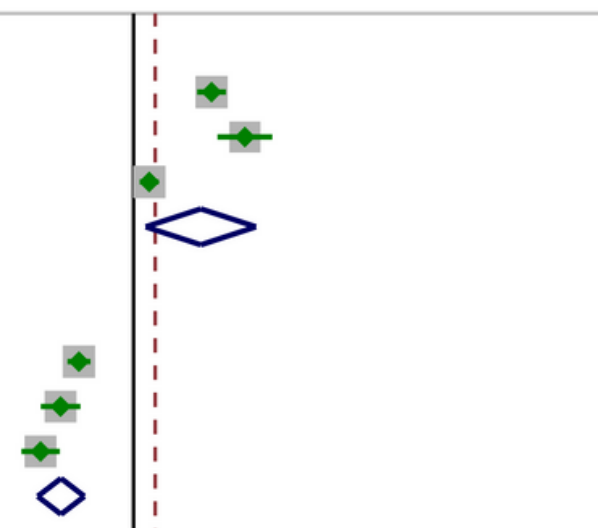

$4.33(3.53,5.13) \quad 6.07$

$6.18(4.66,7.71) \quad 5.53$

$0.87(0.34,1.40) \quad 6.20$

$3.74(0.68,6.80) \quad 17.80$

$-3.03(-3.67,-2.39) \quad 6.15$

$-4.05(-5.15,-2.95) \quad 5.87$

$-5.16(-6.23,-4.09) \quad 5.90$

$-4.03(-5.32,-2.73) \quad 17.93$

$1.97(1.44,2.50) \quad 6.20$

$2.23(1.43,3.03) \quad 6.07$

$4.72(3.73,5.72) \quad 5.95$

$2.93(1.43,4.42) \quad 18.22$

$1.82(1.30,2.34) \quad 6.20$

$-0.12(-0.53,0.29) \quad 6.24$

$0.18(-0.35,0.72) \quad 6.20$

$-0.75(-1.49,-0.01) \quad 6.10$

$20.24(15.65,24.83) \quad 2.78$

$2.37(1.71,3.04) \quad 6.14$

$0.20(-0.08,0.48) \quad 6.27$

$-0.94(-1.64,-0.24) \quad 6.12$

$1.07(0.11,2.04) \quad 46.06$

$1.20(0.18,2.23) \quad 100.00$

\section{Figure 5}

Forest plot of the blood gas index. 
Study

ID

$\operatorname{RR}(95 \% \mathrm{CI})$

$\%$

Overall adverse events

PL Li 2018

JS Liu 2018

P Long 2018

DJ Sun 2017

XQ Tu 2018

Q Wang 2017

H Yan 2017

YZ Yuan 2017

H Li 2013

J Liang 2016

ZM Liang 2016

Y Wu 2014

Y Yang 2016

Y Ding 2016

XM Huang 2016

Subtotal $(\mathrm{I}$-squared $=0.0 \%, \mathrm{p}=0.511$ )

Aspiration

Y Ding 2016

XM Huang 2016

XQ Tu 2018

J Liang 2016

Y Wu 2014

Subtotal $(\mathrm{I}$-squared $=0.0 \%, p=0.693$ )

Heterogeneity between groups: $p=0.016$

Overall (I-squared $=10.6 \%, p=0.322$ )

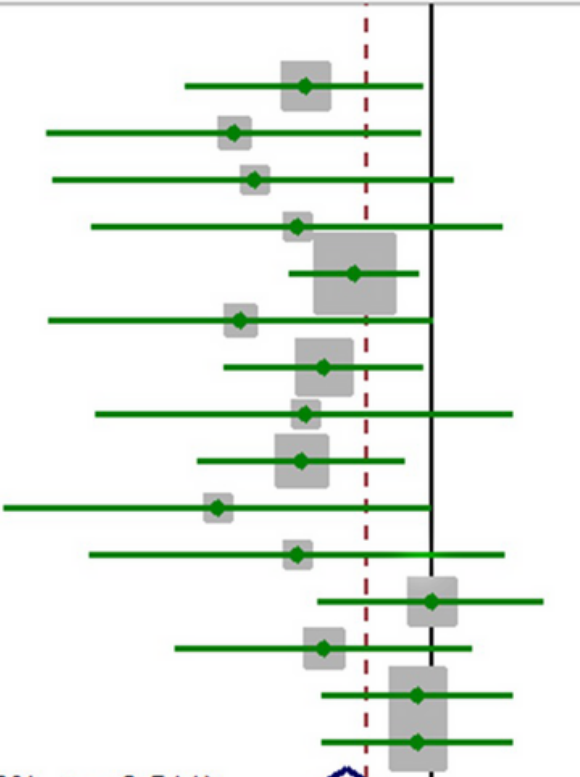

$0.27(0.08,0.92) \quad 5.10$

$0.13(0.02,0.90) \quad 2.04$

$0.16(0.02,1.27) \quad 1.77$

$0.25(0.03,2.10) \quad 1.68$

$0.45(0.23,0.88) \quad 16.91$

$0.14(0.02,1.02) \quad 1.93$

$0.33(0.12,0.92) \quad 7.26$

$0.27(0.03,2.34) \quad 1.63$

$0.26(0.09,0.76) \quad 6.61$

$0.11(0.01,1.00) \quad 1.57$

$0.25(0.03,2.13) \quad 1.66$

$1.00(0.31,3.21) \quad 5.60$

$0.33(0.07,1.54) \quad 3.21$

$0.86(0.32,2.32) \quad 7.73$

$0.86(0.32,2.32) \quad 7.73$

$0.41(0.30,0.57) \quad 72.44$

$0.86(0.32,2.32) \quad 7.73$

$0.86(0.32,2.32) \quad 7.73$

$0.89(0.38,2.09) \quad 10.42$

$0.20(0.01,4.00) \quad 0.85$

$5.00(0.25,100.48) \quad 0.85$

$0.88(0.52,1.49) \quad 27.56$

$0.51(0.38,0.67) \quad 100.00$

\section{Figure 6}

Funnel plots of overall adverse events and aspiration.
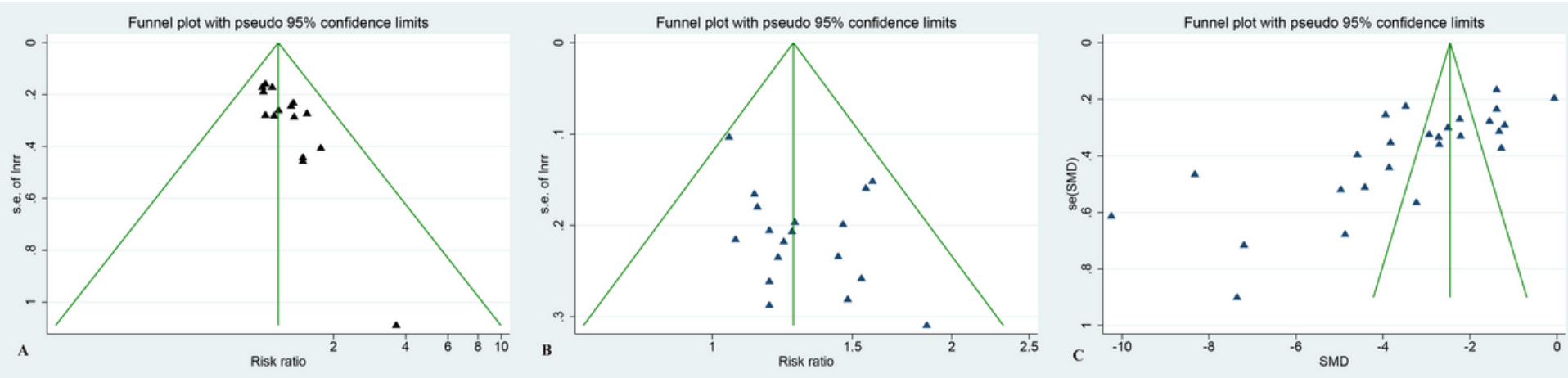
Figure 7

Funnel plots of the ventilation efficiency rates (A), the success rates of first intubation (B) and insertion times (C).

\section{Supplementary Files}

This is a list of supplementary files associated with this preprint. Click to download.

- PRISMA2009checklist.pdf

- Studiesincluded.rar 